\title{
First year students' lived experiences of the third trimester field practical programme at selected communities in the Upper West region of Ghana
}

\section{Mohammed ${ }^{\star}$ and Evelyn Kuusozume Yirbekyaa}

University for Development Studies, Ghana.

Accepted 10 July, 2018

\begin{abstract}
The purpose of this paper was to investigate first year students' lived experiences of the Third Trimester Field Practical Programme at selected communities in the Upper West Region of Ghana. Convenience sampling method was used to select and put students into focus groups. Focus group interview was then used to collect data from the students. Data obtained were analysed thematically. Findings on the students' lived experiences of the Third Trimester Field Practical Programme include: members in the communities lack financial supports to venture into farming and businesses, poor roads network slowed down most economic activities in the communities, there were inadequate social amenities, there were lack of toilet facilities, poor telecommunication network system was prevalent, improper waste disposal was prevalent, there were issues of misunderstanding among students due to individual differences, students had financial troubles, there was an acute shortage of decent rooms for students, there were shortage of first aid drugs in most Community-based Health Planning and Services (CHPS) compounds and there was a lack of portable drinking water. Potentials possess by the communities include: vast land for economic activities, active labour force, sheanut trees for shea butter processing and the availability of CHPS compounds in some communities. The benefits of the Field Practical Programme include: students learning all the socialization techniques, students been able to adjust into rural and deprived community life, students been exposed to places, culture and beliefs of other communities, students acquiring the team work spirit and students been able to into practice in the communities the knowledge learnt in the classroom. Recommendations were made concerning the developmental challenges in the communities and how the communities' potentials can be turned into viable developmental projects and businesses.
\end{abstract}

Keywords: Trimester, field, practical, programme, community, CHPS compound.

*Corresponding author. E-mail: ssh.mohammed@yahoo.com. Tel: +233555002049, +233542417991.

\section{INTRODUCTION}

The University for Development Studies (UDS) has adopted practically oriented methodologies to teaching and learning, research and outreach services in fulfilling its mandate one of blending the academic world with that of the community in order to provide constructive interaction between the two for the total development of Northern Ghana in particular and the country as a whole (Yakubu, 2015). The University for Development Studies (2018) published on its website that one of its unique features is the fact that it has successfully blended its academic programmes with the intensive communitybased field practical training, dubbed the Third Trimester Practical Programme (TTFPP).

A whole third trimester in the university is devoted solely to practical field work in the local communities (Yakubu, 2015). Students of a given year group are posted to specific communities of a given region where they spend eight weeks over a period of three (3) years (Stanley, 2017; Azabre, 2013). Since the inception of the TTFPP in 1993, the programme has recorded a 
successful community-based field practical training which to an extent made it possible for the university to embark on an integrated approach to the TTFPP (UDS, 2018).

According to Azabre (2013) since the inception of the UDS in 1992 (and backed by PNDC Law 279), it has grown significantly in all aspects including campuses, programmes and physical development. UDS was established to accelerating development in the Northern part of Ghana, to close the developmental gap that exists between the North and South, and to ensure the total development of the country (Azabre, 2013). One of the most outstanding features of the UDS is its TTFPP which is specifically devoted to community work (Azabre, 2013).

\section{Concept and rationale of the integrated TTFPP}

The Integrated Third Trimester Field Practical Programme entails the combination of students from all the faculties/schools who tackle developmental problems in selected communities (UDS, 2018). This Integration enables students to see community developmental challenges and prospects from different angles (UDS, 2018). Azabre (2013) highlights that UDS has distinguished itself as a pro-poor based, academically inclined, results-oriented and field-based as well as development focused University in the whole of Ghana. With limited infrastructure, the University still commands a great deal of retrospect in advancing the academic excellence in the country.

\section{General objectives of the TTFPP}

UDS (2018) and Yakubu (2015) outline the following general objectives of the TTFPP: the TTFPP ensures an effective interaction between students, staff and the local communities which aims at facilitating socio-economic transformation; it exposes both students and lecturers to the nexus of development problems of deprived communities in Ghana and particularly in Northern Ghana practically; it fosters favourable attitudes in students towards working in deprived communities; it supports the District Assemblies, local communities and other development actors to implement and sustain the government's decentralization and other pro-poor programmes; it ensures the University provides useful services aimed at satisfying the developmental needs and aspirations of communities and lastly, it informs the research work, teaching and learning activities of the University geared towards solving community problems (UDS, 2018; Yakubu, 2015).

\section{Content and organisation of TTFPP}

The UDS students are offered the ladle to serve their receptive accommodating communities with plates of applicable knowledge they acquired in the classroom (Stanley, 2017). They might not have the capacity to solve identified development gutters in their communities but are to a far end handsomely equipped to propound possible solutions (UDS, 2018; Stanley, 2017).

The TTFPP is a three year intensive engagement which is an iterative process that introduces the student to community studies in their first year stay, where they wholly assess the community (UDS, 2018; Stanley, 2017). Deployment of students to the community is normally preceded by orientation (UDS, 2018), on the orientation, Yakubu (2015) explains that the orientation equips students with the necessary skills to enable them together with the community members collect and analyse information leading to the preparation of a community profile.

Yakubu (2015) and Stanley (2017) explain that second year students (L200s) of the University are required to build on what was done in the previous in a given community by identifying development problems, challenges and coming out with solutions to the identified problems and challenges. In the third year, students together with community members join hands in formulating interventions meant for solving key developmental problem areas in the communities (UDS, 2018). During the orientation period, students are entreated to make adequate preparations for the period and to have sufficient logistics to meet their housing, lodging and health requirements (Yakubu, 2015).

\section{Student assessment}

The assessment of students on the TTFPP is done in specific areas such as: orientation to the programme, community entry, seminars and workshops in the community and written reports presented by the students (UDS, 2018). The assessment is conducted in each community by a multi-disciplinary team of assessors. Students are assessed and graded at the end of each TTFPP session (Yakubu, 2015). A zero score in any of the areas of assessments leads to a final zero score of the total assessment. In addition, a student obtaining less than $75 \%$ (that is, more than 12 days of absenteeism) also fails the entire programme (Yakubu, 2015).

\section{Benefits of the third trimester field practical programme to students}

The benefits accrued to students when they embark on the TTFPP includes: learning about the socio-cultural differences in Ghana, learning to live and work with different cultural groups, and to tolerate the different cultural values and practices in the country (Azabre, 2013). 
Azabre (2013) and Stanley (2017) claim that the TTFPP gives students the opportunity to put classroom knowledge into field practice, students are again giving opportunity to learn group dynamics, team work and group leadership and to appreciating the development needs of the average Ghanaian. A story narrated by Azabre (2013:3) on the benefits of the TTFPP from a student's perspective is:

I have never known that life is not linear. I was born and raised in city and I thought Ghana is in Accra. I never knew that there is life outside Accra. But today, I have come to appreciate life outside the city. Had it not been UDS I would have lost completely. I thank UDS for giving me such life experience. I promise I will set-up an NGO to take care of the disadvantaged people in rural areas in Ghana after my completion. God bless UDS and long live TTFPP.

\section{MATERIALS AND METHODS}

A case study design was used in this study in order to ascertain first year students lived experiences of the Third Trimester Field Practical Programme (TTFPP) organized by the University for Development Studies and to establish how their experiences could be addressed to ensure effective implementation of the TTFPP. The design was chosen as it serves as an evidence-based inquiry into the students' lived experiences in the communities. The design is also an empirical approach that focused on an intense investigation of real-life context of the Third Trimester Field Practical programme (Eunjung et al., 2010). The study was confined to only second year students (L200) of the Faculty of Education.

Convenience sampling method was used to select and put students into focus groups of not less than six students in a group. In all, there were fourteen (14) focus groups of which there were eight (8) students per group. The grouping was carved out of an orientation programme organized on students' feedback from the first year Third Trimester Field Practical Programme carried out and to also prepare them towards the TTFPP community re-entry in the second year. The grouping was based on the different communities students carried out their Field Practical Programme. Students were conveniently selected and grouped with the belief that quick approximation of the truth in relations to their experiences in the communities and the objectives of Third Trimester Field Practical Programme would be ascertained (Louse et al., 2009; Maree, 2010).

Focus group interview method was used to collect data from students through note taking. The interview comprised not less than six students in a group from each of the different communities that students spent their Field Practical Programme. This was to discuss issues surrounding the Third Trimester Field Practical programme where two lecturers were involved as the moderators who created a setting where students felt comfortable enough to reflect and describe in a two hour dynamic discussions of their experiences of the Third Trimester Field Practical programme (Hennink, 2007; Liamputtong, 2011).

In general, all semi-structured interviews questions asked were found to be clear to the participants (Pathak and Intratat, 2012). Permission to carry out the study was sought from students and were also assured that their private world and responses would be kept confidential and used only for the purpose of the study (Liamputtong, 2011). A thematic analytical technique was used to analyse the data. The data were rigorously and systematically read and transcripts coded to allow for major themes to emerge; this was where data were read to become familiar with, they were examined to provide detailed descriptions of participants' words and responses, data were categorized, coded and then finally grouped into themes (David, 2003).

\section{RESULTS}

The results of the study based on the research objective and question are: (i) developmental challenges faced by communities from students perspectives, (ii) developmental challenges faced by communities from community members perspectives, (iii) potentials possess by the communities from students perspectives, (iv) common challenges in the communities faced by students and $(\mathrm{v})$ the benefits of the Third Trimester Field Practical Programme to students.

\section{DISCUSSION}

\section{Developmental challenges in the communities from students' perspectives}

The study revealed that the various communities where students spent their TTFPP service have numerous developmental challenges which include: lack of financial supports to members to venture into farming and other businesses, inadequate market for farm produces to be sold and to facilitate the buying and selling of other goods and there were the prevalence of poor sanitation and poor drainage systems resulting into breeding grounds for mosquitoes and other insects. A student had this to say:

You see madam, the community we were sent had inadequate market for farm produce and less business activities going on there. Another student lamented as: the challenge was that most community members had no financial 
support to help them venture into farming and agricultural activities. A third student expressed the following: in our community, there was poor sanitations and poor drainage system.

The finding is consistent with the finding of Kwasi (2014), that sanitation has become a major issue of concern to the residents of Elubo which is an urban settlement in the Jomoro District of Western Region. The town is engulfed in filth and cannot even boast of one public toilet facility as well as a landfill site (Kwasi, 2014).

It was also found that poor roads network slows down most economic activities in the communities, inadequate social amenities which have the power of providing comfort, convenience and enjoyment for community members, lack of toilet facilities that result into open defecation practices in most communities, poor telecommunication network that hinders a smooth transmission and exchange of information in the communities and the prevalence of improper waste disposal in the communities resulting to high incident of diarrhea and other chronic sicknesses were some additional developmental challenges faced by the communities. A student's experience in one community was:

In our community, the drainage system was poor, there were not toilet facilities and the road network in some of the communities was poor. Another student lamented as follows: We had incident of diarrhea and other sicknesses because of improper disposal of waste.

To confirm the findings on lack of toilet facilities that results into open defecation practices in most communities, Ambesh and Ambesh (2016) highlight that the practices of open defecation is one of the major sanitation issues facing the world today and can be described as Africa phenomenon.

In a related developmental challenges in some Ghanaian communities, Samuel et al. (2013) confirms the above findings by highlighting that attempts by the government, the IMF and the World to halt the declining trends of poor living standards of people and to create a conducive atmosphere to sustained economic growth and prosperity has been achieved with minimal success.

\section{Developmental challenges in the communities from community members perspectives}

The study also revealed that students during their stay in the communities did interact with community members who identified the following as the most developmental challenges they faced and are: the lack of dams and the difficulties in accessing potable water as a result, there is fewer irrigation practices in the communities, the lack of financial and agricultural inputs support from the government, the lack of agriculture extension officers in the communities, the lack of basic social amenities and recreational centers and the prevalence of poor road network that act as stumbling blocks to rapid economic activities. Two students made the following comments which represent the community members' views:

What they mentioned as the biggest challenges in our community were the difficulties in accessing potable water and the lack of support from government to help them get into farming. And: In our community, they mentioned lack of basic social amenities, lack of dam and the difficulties in accessing farm inputs as their challenges.

Kwasi (2014) confirms the findings when he claims that poor condition of roads in some towns is one of the major development problems impeding the flow of traffic and the high generation of dust makes it impossible for Assemblies to construct modern market. In response to these challenges, Jim (2001) opines that rural community vitality depends on communities maintaining adequate infrastructure, having access to services, enhancing business and economic opportunities and establishing policy settings to foster outcomes.

\section{Potentials possess by the communities from students perspectives}

It was found in the study that communities in which students lived during the TTFPP service possess potentials which include: active labour force as most of the members in the various communities were made up of the youth who make up the active labour force in the communities, there were lots of Sheanut trees where members could venture into sheanut processing business and there were CHPS compounds with qualified health workers to deliver essential community-based health services. A student's opinion was:

Doctor you see, though there were challenges in our community but they have active labour force of young guys and ladies and there were Sheanut trees in our community. Another student said the following: What we saw as potentials were the availability of CHPS compound and qualified personnel (Health and Education workers) in the community.

Jim (2001) suggest that if the potentials posses by the communities is to be harnessed, the local economy and social system must function well, there should be the sustenance of employment and there should be the sustenance of population and quality of life in the 
communities.

It was also found that most communities possess vast land that could be acquired cheaply for farming and other agricultural practices, there were pasture and animals for livestock farming, there was a high level of community norms and values, there were natural water bodies, there was cheap labour as most of the youth are unemployed and take any wage as payment if engaged in businesses and other agricultural activities and there was the existence of rocks for quarrying in some communities. A student said the following:

The community we were had vast land for farming, the rearing of animals and the presence of natural water bodies. Another student mentioned the following potentials: There was an easy acquisition of land and there was the existence of rocks for quarrying in our community.

In other to harness the potentials found in the communities, Jim (2001) opined that social and economic changes in communities can only come true if steps to ensure infrastructure and economic development are put in place, if local people can work cooperatively, improving networks, mobilizing existing skills, and put innovative ideas into action.

\section{Common challenges in the communities faced by students}

The study found the following common challenges students face in their various communities: there were barriers to communication between the students and community members which to some extent slows down dialogue and information sharing, there was misunderstanding among students due to individual differences, there were financial constraints, acute shortage of decent and well furnished rooms, absence of social amenities, shortage of drugs and first aids in most CHPS Compounds, poor drainage system, poor waste disposal methods, lack of restaurants and potable drinking water and poor network system in the communities. A student lamented in the following way:

Hmm madam, some of us faced communication barrier since it was not easy exchanging ideas with some community members. Another student views were: What we can say is that there was a lack of understanding among students; we had financial problems too and we had accommodation challenges. A third student mentioned the following: We suffered from harmful insects in the community and lack of nutritional food and potable drinking water.

The above findings concur with Mohammed (2015) findings that most communities around Elliotdale in the Eastern Cape of South Africa have few roads tarred which as a result add to the economic challenges in those communities, some communities have limited access to basic services such as schools, and healthcare facilities. Teachers in most communities faced an acute shortage of accommodation, live in unsafe and unsecured surroundings to work (Mohammed, 2015).

The findings are also in consistent with the findings of Biradar (2014) and Othman and Yuhaniz (2013). Anaman and Nyadzi (2015) who claim that the developmental challenges in most communities include: poor waste disposal, the lack of compliance with the laws governing waste disposal, the lack of access to containers meant for the collection of waste, the lack of knowledge in recycling and the failure of the District Assembly to ensure that laws governing waste disposal are adhered to by households.

\section{Benefits of the third trimester field practical programme to students}

The study revealed that there are many benefits accrued to students when they embark on Third Trimester Field Practical Programme; some of which are: the programme helps students to learn all the socialization techniques among themselves and how to interact with community members, the programme equips students lifelong team spirit, it helps students to be able to adjust in rural and deprived community working life, the programme gives students the opportunity and exposure to places, culture and beliefs of other communities and the programme offers students the opportunity to put into practice in the communities the knowledge learnt in the classrooms. The following benefits were mentioned by a student:

The TTFPP has helped me to learn how to socialize with other people; it gave me a spirit of team work. Another student's opinion was that: The field programme in the communities helps us to adjust ourselves towards working in rural and deprived communities. A third student said the following: I think it gives students the opportunity to know places they would not have been to and it exposes students to different cultures.

The finding is in consistent with the concept and rationale of the integrated TTFPP upholds by the UDS. The UDS (2018) upholds that the integration TTFPP broadens the knowledge and experience of students, as they have the opportunity to interact and learn from each other and also fosters in students the spirit of team work, which is very essential for work in a world that is becoming increasingly complex and requiring collective efforts to overcome challenges. The finding concurs with Azabre (2013) findings that the team spirit, the spirit of serving in a given 
society, commitment, appreciation and valuing working life in rural areas are some benefits of the TTFPP to students.

\section{CONCLUSION}

Despite the key role play by the University for Development Studies in blending the academic world with that of the community, there are still developmental challenges faced by communities in the Northern part of Ghana. There are also numerous challenges faced by students in communities and to fully benefits from the general objectives of the Third Trimester Field Practical Programme. Issues of lack of financial supports to community members to venture into farming and other businesses, inadequate market for farm produces to be sold, poor drainage systems, poor roads network and the prevalence of improper waste disposal in the communities were some of the developmental challenges in the communities. The potentials possess by the communities include: active labour force, availability of sheanut trees, availability of CHPS Compound with qualified health workers, vast land for farming and other agricultural practices and the existence of rocks for quarrying in some communities. It can be possible to harness the potentials in the communities only if the developmental challenges are eliminated or minimized to some extent. The Third Trimester Field Practical Programme could be a success if challenges such as barriers to communication between the students and some community members, issues of financial problems faced by students, the acute shortage of decent rooms, the absence of social amenities, the presence of mosquitoes and other harmful insects, the lack of restaurants and portable drinking water and the poor network system in the communities could be minimized. The benefits accrued to students when they embark on the Third Trimester Field Practical Programme include: learning all the socialization techniques among themselves and with the community members, adjusting and developing positive attitudes towards working in deprived communities, acquiring a spirit of team work, students putting into practice in the communities the knowledge learnt in the classroom, getting the opportunity to visit new places and towns and getting the opportunity to be exposed to different culture and beliefs in the country.

\section{RECOMMENDATIONS}

It is recommended that the chiefs in the various communities should work with their districts to allocate farm lands to all members in the communities and to also join forces with experts in agriculture and farming for their expertise. The Ministry of Agriculture should work hand in hand with financial institutions to secure financial assistance for community members to farm productively. It is also recommended that various districts should work with the government and Non Governmental Organisation to assist them with dams and irrigation farms.

The University for Development Studies must be in talks with the chiefs, the ministry of agriculture, the districts and some identified Non Governmental Agencies to set up sheanut and dawadawa (Parkia biglobosa) processing factories in each of the communities and to involve members in the day-to-day running and operation of those machines. The University for Development Studies in collaboration with the districts must identify potential business partners to venture into livestock rearing, communication and recreational businesses; these partners must be encouraged to employ the youth so as tap into their energy and potentials. Viable, modern and functional market facilities must be put up in each of the communities through the efforts and collaboration between the chiefs, businesses and the districts.

The districts must work with environmental protection agencies, the ministry of roads and works and sanitation agencies to improve the drainage systems in the communities and to construct good roads to link major communities. The chiefs must collaborate with Nongovernmental Agencies must construct toilet facilities for each house hold in the communities. The district, chiefs and the Ministry of Health should intensify their goals for the CHPS compound and to ensure there is adequate supply of drugs in each compound. The University for Development studies must make partnership with the chiefs, the University of Mines and Technology and the minister of land and natural resources to start quarrying operations in communities where the rocks are deposited.

It is also recommended that when posting students to communities, at least few students might be conversant with the language spoken in that community so they could act as mediators between the student and the community members. Students must also be properly oriented by coordinators to put their difference aside when in the communities and to work towards the main goals of the TTFPP. Students must also be made to properly and adequately prepare financially when embarking on community programmes. The TTFPP Directorate, the Estate Directorate of the University of Development Studies, the chiefs and opinion leaders in each community must work hand in hand to secure students with portal drinking water, safe, adequate and well furnished rooms for the duration of their stay in the communities.

\section{REFERENCES}

Ambesh, P., and Ambesh, S. P. (2016). Open defecation in India: A major health hazard and hurdle in infection control. Journal of Clinical 
and Diagnostic Research, 10(7): IL01-IL02.

Anaman, K. A., and Nyadzi, W. B., (2015). Analysis of improper disposal of solid wastes in a low-income area of Accra, Ghana. Applied Economics and Finance, 2(1): 66-75.

Azabre, I. A., (2013). Education in Focus: The UDS Field Practical Training Programme (TTFPP) And The Need For Other Universities To Adopt Similar Programmes (Online). Available at https://www.modernghana.com/news/445116/education-in-focus-theuds- Accessed: 28th March, 2018.

Biradar, B. (2014). Awareness of Solid Waste Management Among Under Graduate Students in Hydrabad, Karnataka Region. EPRA International Journal of Economic and Business Review, 2(10): 4147.

David, R. T. (2003). A General Inductive Approach for Qualitative Data Analysis [Online]. Available at: http://www.fmhs.auckland.ac.nz/. Accessed: $20^{\text {th }}$ March, 2018.

Eunjung, L., Faya, M., and Sara, B. (2010). How to Evaluate Case Studies in Social Work. (online). Available at: http://www.sage publications.com. Accessed: $13^{\text {th }}$ February, 2018.

Hennink, M. M. (2007). International focus group research: A handbook for the health and social sciences. Cambridge: Cambridge University Press.

Jim, C. (2001). Rural Community Development - New Challenges and Enduring Dilemmas. [Online] Available at: https://ageconsearch. umn.edu/bitstream/. Accessed $27^{\text {th }}$ April, 2018.

Kwasi, P. (2014). Development Problems and Challenges In Urban Areas: A Case Study of Elubo. Available at https://www.ghanaweb. $\mathrm{com} /$ GhanaHomePage. Accessed $20^{\text {th }}$ April, 2018.

Liamputtong, P. (2011). Focus Group Methodology: Principles and Practice. London: Sage.

Louse, C., Lawrence, M., and Keith, M., (2009). Research Methods in Education. Sixth edition. New York City: Routledge.

Maree, K. (2010). First Steps in Research. Sixth impression. Pretoria: Van Schaik.

Mohammed, I. (2015). Factors Impacting on Teachers' Professionalism at Secondary Schools in the Elliotdale Circuit of The Dutywa Education District. Unpublished Doctoral Thesis.

Othman, A. R., and Yuhaniz, M. (2013). Awareness among terrace house residents in Shah Alam towards domestic waste recycling. Journal of Asian Behavioural Studies, 3(11):13-26.

Pathak, A., and Intratat, C. (2012). Use of semi-structured interviews to Investigate teacher perceptions of student collaboration. Malaysian Journal of ELT Research, 8 (1): 1-10.

Samuel, Z. B., Arkum, T. A., and Owusu-Sekyere, E., (2013). Community Development in Ghana: Theory and Practice. European Scientific Journal. 9(17): 1857-7881.
Stanley, S., (2017). UDS Third Trimester Field Practical Programme (TTFPP): Addressing the Erroneous Views. (Online). Available at http://uds360.com/2017/05/24/uds-third-trimester-field-practicalprogramme- Accessed: $12^{\text {th }}$ April 2018.

University for Development Studies (UDS) (2018). Third Trimester Field Practical Programme. (Online). Available at https://www.uds.edu.gh /research/third-trimester-field-practical-programme. Accessed: 19th April 2018.

Yakubu, Y. (2015). TTFPP Level 200 Field Guide. (Online). Available at https://yakubusblog.wordpress.com/2015/07/22/8/. Accessed: April $1^{\text {st }} 2018$.
Citation : Mohammed, I., and Yirbekyaa, E. K. (2018). First year students' lived experiences of the third trimester field practical programme at selected communities in the Upper West region of Ghana. African Educational Research Journal, 6(3): 130-136. 